O senhor não sabe o que é orelha de pau, né? É, a gente comia. Anciã, Comunidade Quilombola Volta Miúda.

HUMANAS E SOCIAIS

V.9 • N.2 • 2021 • Fluxo Contínuo

ISSN Digital: 2316-3801

ISSN Impresso: 2316-3348

DOI: $10.17564 / 2316-3801.2021 v 9 n 2 p 401-416$
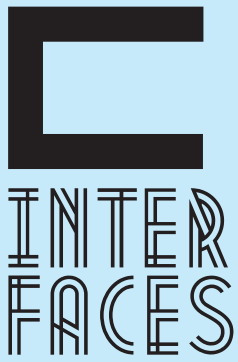

CIENTÍFICAS

\title{
ANCESTRALIDADES E MEMÓRIAS: PLURIEPISTEMOLOGIASE INTERCULTURALIDADE NA EDUCAÇÃO BÁSICA
}

ANCESTRALITIES AND MEMORIES: PLURIEPISTEMOLOGIES AND INTERCULTURALITY IN BASIC EDUCATION

ANCESTRALIDADES Y MEMORIAS: PLURIEPISTEMOLOGÍASE INTERCULTURALIDAD EN LA EDUCACIÓN BÁSICA

Francisco Antonio Nunes Neto ${ }^{1}$ Pedro Rodolpho Jungers Abib ${ }^{2}$

\section{RESUMO}

Parte integrante das análises que estão sendo realizadas na pesquisa do estágio pós-doutoral, este artigo discute de que maneira, em que medida e em quais sentidos, por meio da conjunção entre ancestralidades, memórias, pluriepistemologias e interculturalidades, é possível efetivar processos de produção de conhecimento no contexto da educação básica. Neste sentido, as discussões e questões apresentadas ao longo do artigo dialogam, de alguma maneira, com outras análises sobre a descolonização do pensamento, forma de produção de conhecimento que, em diálogos permanentes com as nossas tradições culturais e com os saberes populares que emergem e se relacionam com os povos e comunidades indígenas e quilombolas, visam contribuir nos processos de (re)educação das relações de sociabilidades culturais para que (re)aprendamos ou (re)elaboremos as nossas percepções enquanto sujeitos históricos, principalmente, no cômputo dos processos de (re)descoberta, identificação e fortalecimentos das identidades socioculturais. 0 campo onde a pesquisa está sendo realizada é formado pelas comunidades remanescentes de quilombo Arara, Volta Miúda, Helvécia e Rio do Sul; indígenas Pataxó das Aldeias Cahy, Corumbauzinho e Boca da Mata; e Pataxó Hã-Hã-Hãe da Aldeia Renascer localizadas na região Extremo Sul do estado da Bahia. Neste texto, apresento, parcialmente, um recorte da pesquisa realizada nas comunidades remanescentes de quilombo Arara e Volta Miúda e indígenas Cahy, Corumbauzinho Boca da Mata e Renascer. 


\section{PALAVRAS-CHAVE}

Ancestralidades. Memórias. Pluriepistemologias. Interculturalidades.

\section{ABSTRACT}

An integral part of the analyzes that are being carried out in the research of the Postdoctoral Programme, this article discusses how, to what extent and in what ways, through the conjunction of ancestry, memories, pluriepistemologies and interculturality, it is possible to accomplish processes of knowledge production in the context of basic education. In this sense, the discussions and questions presented throughout this article dialogue, in some way, with other analyzes on the decolonization of thought, a form of knowledge production that, in permanent dialogues with our cultural traditions and with the popular knowledge that emerge and relate to indigenous and quilombola peoples and communities, aim to contribute to the processes of re-education of cultural sociability relations so that we can relearn or re-elaborate our perceptions as historical subjects, mainly in the computation of the processes of (re)discovery, identification and strengthening of socio-cultural identities. The field where the research is being carried out is formed by the remaining quilombo communities Arara, Volta Miúda, Helvécia and Rio do Sul; Pataxó Indigenous people from the Cahy, Corumbauzinho and Boca da Mata villages, and Pataxó Hã-Hã-Hãe from the Renascer village located in the extreme south of the state of Bahia. In this article, we present, in part, an excerpt of the research carried out in the remaining quilombo communities of Arara and Volta Miúda and in the indigenous people of Cahy, Corumbauzinho, Boca da Mata and Renascer village.

\section{KEYWORDS}

Ancestry. Memories. Pluriepistemologies. Interculturality

\section{RESUMEN}

Como parte integral de los análisis que se llevan a cabo en la investigación de la práctica profesional posdoctoral, este artículo analiza cómo, en qué medida y de qué manera, a través de la conjunción de antepasados, recuerdos, pluriepistemologías e interculturalidades, es posible conducir procesos de producción de conocimiento en el contexto de la educación básica. En este sentido, las discusiones y preguntas presentadas a lo largo del artículo dialogan, de alguna manera, con otros análisis sobre la 
descolonización del pensamiento, una forma de producción de conocimiento que, en diálogos permanentes con nuestras tradiciones culturales y con el conocimiento popular que emerge y se relacionan con pueblos y comunidades indígenas y quilombolas, tienen como objetivo contribuir a los procesos de (re)educación de las relaciones de sociabilidad cultural para que podamos (re)aprender o (re)elaborar nuestras percepciones como sujetos históricos, principalmente en el cálculo de los procesos de (re)descubrimiento, identificación y fortalecimiento de identidades socioculturales. El campo donde se lleva a cabo la investigación está formado por las comunidades quilombo restantes Arara, Volta Miúda, Helvécia y Rio do Sul; Indígenas Pataxó de los pueblos Cahy, Corumbauzinho y Boca da Mata; y Pataxó Pode-Hãe da Aldeia Renascer, ubicado en la región del extremo sur del estado de Bahía. En este texto, presento, en parte, un extracto de la investigación realizada en las comunidades restantes de quilombo Arara y Volta Miúda y Cahy, Corumbauzinho Boca da Mata y Renascer.

\section{PALABRAS CLAVE}

Ancestralidad. Memoria. Pluriepistemologias. Interculturalidad.

\section{INTRODUÇ̧̃̃O}

A região Extremo Sul da Bahia é formada pelas cidades Alcobaça, Caravelas, Ibirapuã, Itamaraju, Itanhén, Jucuruçu, Lajedão, Medeiros Neto, Mucuri, Nova Viçosa, Prado, Teixeira de Freitas e Vereda. É este o território geográfico, cenário e campo onde a pesquisa que possibilitou a elaboração deste artigo está sendo realizada.

Trata-se da pesquisa em elaboração no estágio pós-doutoral e que busca compreender de que maneira, em que medida e em quais sentidos os saberes populares tradicionais das comunidades indígenas Pataxó das Aldeias Cahy, Corumbauzinho e Boca da Mata; Pataxó Hã-Hã-Hãe da Aldeia Renascer e das comunidades remanescentes de quilombos rurais e urbanos Arara, Volta Miúda, Helvécia e Rio do Sul podem contribuir, por meio da conjunção das ancestralidades, memórias, pluriepistemologias e interculturalidades, na promoção de práticas de ensino-aprendizagem, pelas quais, os processos civilizatórios das comunidades e povos tradicionais da região sejam valorizados e introduzidos na produção de conhecimentos no contexto da educação básica.

As comunidades que se constituem campo desta pesquisa se localizam, fundamentalmente, nas cidades Itamaraju, Alcobaça e Teixeira de Freitas e foram delimitadas à medida em que guarda entre si, melhor possibilidade de trânsito, o que, para os objetivos e tempo envidado na pesquisa de campo, se constituiu como de singular importância, haja vista, o exíguo tempo de doze meses para a realização da empreitada que é conseguir circular por aquelas cidades e localidades.

As questões norteadoras da pesquisa de campo e que possibilitaram o desenvolvimento das interlocuções com alguns moradores das comunidades, foram: i) quais são as contribuições culturais que 
os povos indígenas/quilombolas podem nos dar para um melhor entendimento sobre quem somos? ii) quais são os saberes tradicionais locais desta comunidade? e iii) de que maneira estes saberes tradicionais são transmitidos entre as diferentes gerações? Embora ao longo das interlocuções outras perguntas tenham sido lançadas, as anteriormente apresentadas foram as questões-eixos que nos possibilitou o desenvolvimento da pesquisa e dos resultados a que cheguei e apresento, parcialmente, neste escrito.

Para o estudo das comunidades indígenas e quilombolas do Extremo Sul da Bahia e suas sociabilidades culturais, já dispomos de uma literatura. Dentre estes estudos, os elaborados por Alane Fraga do Carmo (2010), Gean Paulo Gonçalves Santana (2014) e Valdir Nunes dos Santos (2017) sobre as comunidades remanescentes de quilombos localizadas em Helvécia e Rio do Sul em Nova Viçosa, se constituem referências singulares e imprescindíveis; o mesmo pode-se dizer sobre as contribuições valiosas dos estudos elaborados por Maria Geovanda Batista (2010) e Helânia Thomazine Porto (2019) sobre os Pataxó. Entretanto, face a imensidão daqueles territórios, outras pesquisas e estudos certamente contribuirão para melhor conhecê-los.

No âmbito das discussões sobre ancestralidades, memórias, pluriepistemologias e interculturalidades, dialogamos com os estudos elaborados por Anibal Quijano (2005), Daniel Mato (2009), Catherine Walsh (2009, 2017), Muniz Sodré (2017), Pedro Rodolpho Jungers Abib (2019), dentre outros deste campo de produção de conhecimentos que tem fomentado a realização de pesquisas e estudos na seara dos Estudos Culturais e do Pensamento Decolonial.

O projeto de pesquisa inicial intitulado “Descolonizar a cultura: os mestres e as mestras dos saberes populares tradicionais na Escola Básica e as práticas socioeducativas no Extremo Sul da Bahia” foi aprovado no Edital Interno nº 02/2019 na Seleção de Candidatos(as) para a Bolsa PNPD/CAPES do Programa de Pós-Graduação em Educação da Universidade Federal da Bahia, para um período de 12 (doze) meses contados a partir de maio de 2019. Dessa maneira, a pesquisa e os estudos que dela emergirão, visam contribuir nas discussões sobre a reeducação das relações de sociabilidades culturais a partir da introdução do pensamento pluriepistêmico e da abordagem intercultural na educação básica.

O objetivo central que movimenta essa pesquisa - tomando como referências as estratégias epistemológicas e as heranças intelectuais indígenas e quilombolas - é problematizar sobre como introduzi-las e valorizá-las nos contextos de ensino-aprendizagem na educação básica poderá contribuir nos processos de (re)descoberta e fortalecimento das nossas identidades socioculturais e, quiçá, também contribuir para que alguns colegas revisitem as suas práticas docentes de tal maneira que as nossas diversidades e singularidades culturais possam ser melhor abordadas no contexto de uma sala de aula, mas não exclusivamente nelas.

Neste contexto histórico no qual tanto se tem promovido o desmantelo, o sucateamto, a desvalorização da ciência e da produção de conhecimento, estamos precisando reaprender a ser, e para que isso ocorra, teremos que nos (re)conectar com as nossas tradições culturais reconhecendo-as e valorizando-as. Heranças culturais e pluriepistêmicas que poderão, nestes tempos tão sombrios, nos (re)conectar com a natureza tal como praticam os povos indígenas, tal como praticam as populações remanescentes de quilombos rurais e urbanos.

Na pesquisa de campo, as interlocuções foram registradas por meio de suportes audiovisuais portáteis e, neste texto, trechos de alguns registros são apresentados. Neste escrito, optei por não 
revelar nominalmente as pessoas com as quais dialoguei para que mantenham as suas identidades preservadas. Entretanto, no documentário em elaboração, parte integrante dos resultados dessa pesquisa, os/as interlocutores também terão as suas contribuições aí registradas.

Em um estudo anterior (NUNES NETO, 2016) argumentei sobre a importância da formação profissional e continuada no âmbito do ensino das relações étnico-raciais por entender que, mesmo em decorrência da criação de centros de pesquisas, programas de pós-graduação, cursos de graduação e de extensão universitárias no Brasil, ainda haveremos de percorrer um longo caminho para que o resultado dessas formações e qualificações profissionais reverberem. Dizendo de outra maneira, ainda que constatemos haver em diversas regiões e cidades do país a formação e a qualificação dos quadros profissionais docentes no campo da produção de conhecimento do ensino das relações étnico-raciais, o cotidiano das salas de aulas e dos espaços contíguos a elas, ainda é marcado pela subjugação e inferiorização das diferenças, principalmente, quando os diferentes são as pessoas indígenas e negras. Dessa maneira,

[...] em ambos os casos, as histórias dessas populações registram ações torpes e perversas acionadas para sabotar culturalmente as memórias, as histórias, os processos civilizatórios e as formas de ser-estar no mundo de parcelas significativas da população que, no Brasil, sempre foram empurradas para debaixo do tapete de uma história nacional forjada. (NUNES NETO, 2019, p. 40).

Desse modo, as contribuições que objetivo conferir com este artigo intenta somar-se a outras elaboradas sobre este campo de produção de conhecimento. Passemos a elas.

\section{ANCESTRALIDADES, MEMÓRIAS, PLURIEPISTEMOLOGIAS E INTERCULTURALIDADES ENTRE INDÍGENAS E QUILOMBOLAS NO EXTREMO SUL DA BAHIA}

No âmbito das pesquisas e dos estudos elaborados nas Ciências Humanas dispomos de variada literatura sobre as categorias analíticas ancestralidades, memórias, pluriepistemologias e interculturalidade. Contribuições para os estudos das humanidades que emergiram das reformulações teóricas operacionalizadas nas Humanidades, sobretudo, daquelas inauguradas no século anterior sobre os diálogos interdisciplinares.

Aos nossos dias, essas categorias analíticas continuam motivando a produção de conhecimentos e se constituem como esteios por meio dos quais se tem promovido a realização de outras investidas de pesquisa. Neste artigo, as categorias de análise ancestralidades, memórias, pluriepistemologias e interculturalidades são tomadas em conjunção para o entendimento e problematização das estratégias epistemológicas e das contribuições intelectuais dos povos indígenas Pataxó e Pataxó Hã-Hã- Hãe e das populações remanescentes de quilombos localizadas no Extremo Sul da Bahia. Formas se ser-estar-pensar-sentir o mundo que, a rigor, não foram e/ou são estruturantes das concepções de 
currículo e ensino praticadas na história educação deste país, não por acaso, se constituem temas das determinações e preconizações das Leis 10.639/03 e 11.645/08.

No município Prado, em Cumuruxatiba, durante a pesquisa de campo realizada na Aldeia Cahy, uma liderança indígena Pataxó, rememorando as histórias da comunidade e do povo e refletindo sobre o seu entendimento com relação a Lei 11.645/08 analisou que

[...] a gente sabe que há um contexto, assim, dentro dessas leis que a gente nunca consegue realmente fazer ela valer como se deve. E, pra início de conversa [...] nós todos sabemos que, e eu falo como indígena por experiência própria, né? Que tudo conquistado até aqui, foi fruto de luta, de pessoas, antepassados nossos de muito tempo. Fruto esse que foi conquistado através de sangue derramado, né? Através de matanças [...] dentro de comunidades indígena. (CAMPO, 16 de julho de 2019).

Diferentemente do que muitas pessoas ainda acreditam e propagam sobre como vivem e pensam os povos indígenas, em que pese tais ignorâncias, os descendentes dos povos originários ameríndios, sobretudo, nos últimos cinquenta anos, procuraram estratégias de autoproteção e - como na formulação que utilizam - aprenderam a lidar com o "mundo dos brancos" e isso implicou no aprendizado de uma outra cultura, meio pelo qual, das incontáveis aldeias e comunidades espalhadas pelo país e entre os povos que aí habitam, emergiram nomes expressivos que se notabilizaram como ativistas, defensores e intelectuais na defesa dos direitos indígenas.

Dentre eles é possível citar o Cacique Raoni Metuktire (Caiapó), Ailton Alves Lacerda Krenak (Krenak), Sonia Guajajara (Arariboia), Rosivaldo Ferreira da Silva, o Cacique Babau (Tupinambá), Edson Kayapó (Kayapó), dentre algumas outras lideranças que, com os pés fincados em suas tradições culturais, saíram de suas aldeias e, no "mundo dos brancos", aprenderam como este funciona, para, inclusive, se proteger e/ou tentar minimizar a matança e o extermínio a que continuam submetidos.

Por outro lado, "se apropriar" do "mundo dos brancos" em nada se refere a tomá-lo como referência para si, como se fizessem parte deste universo cultural, esquecendo de suas origens. Ao contrário, quanto mais imersos no universo cultural para-além de suas aldeias nas cidades circunvizinhas ou em outras, mais fortalecem as suas identidades socioculturais e suas consciências humanitárias, principalmente, quando as áreas onde habitam se constituem alvos da expansão, ocupação e interesses capitalistas. Nestes termos,

[...] o fato é que, nos anos 70, começou um processo de expropriação e desterritorialização dos Pataxó que veio culminar na luta pela terra e que se fez vitoriosa em 1986. Foi quando o Estado brasileiro respondeu com a Reforma Agrária, com o parcelamento e a demarcação dos lotes de reforma agrária, transformando em assentada cada família Pataxó que participou do movimento de luta. Sua identidade Pataxó foi simplesmente ignorada no contexto e, em lugar dela, veio uma cara nova, uma identidade "nacional”. (BATISTA, 2010, p. 9).

Um povo de cuja presença já tivera sido registrada, desde o século XIX, por meio das lentes e anotações elaboradas por cronistas e viajantes europeus em passagem pela região do Extremo Sul 
da Bahia entre 1815 e 1820 (BATISTA, 2010, p. 6). Logo, a existência Pataxó atravessa sucessivas gerações na história do Brasil. Neste sentido, os "antepassados nossos de muito tempo" evocados pela liderança indígena da Aldeia Cahy representa a sua ancestralidade e as lutas por eles travadas pela sobrevivência do seu povo, herança motriz que tem fomentado na contemporaneidade o ímpeto e a coragem no enfrentamento dos seus direitos. Continuando, a mesma liderança registrou que

[...] o mais interessante é que esses jovens estão vendo que essa luta não, não é a luta pelo dinheiro, não é a luta por um salário, é uma luta por um bem maior que é pro mundo, que é pro Brasil porque já foi feito a pesquisa e eu vi que a maioria dos brasileiros são indígena e afro. (CAMPO. ALDEIA CAHY, 16 de julho de 2019)

A consciência sobre si, mas não apenas para si, veiculada na expressão "parente”, forma de tratamento indígena independentemente das famílias que pertençam, é bastante singular. Pode ser lido como entendem e praticam suas existências em conexão para-além do chão de suas aldeias e em uma relação profícua de respeito, valorização, cuidado e sintonia com a natureza, de onde se alimentam espiritual e materialmente. A natureza-casa indígena lhes possibilita continuar existindo em que pese os ataques e práticas de extermínio constantes. Aí encontram os meios necessários para, entre as distintas gerações, manterem acesas as chamas de suas culturas, acionando para isso, as suas heranças ancestrais e intelectuais, saberes tradicionais a que temos praticado como epistemologias, formas de ser-estar-sentir-pensar o mundo que conecta suas memórias e histórias.

As práticas culturais indígenas de ensino-aprendizagem, por não serem cartesianas, integra os elementos da natureza ao entorno. Em algumas aldeias brasileiras é possível observar a existência de escolas. Nelas - como no Colégio Estadual Indígena de Corumbauzinho -, ainda que os estudantes acessem temas e conteúdos comumente adotados nas escolas não-indígenas, as práticas culturais indígenas são abordadas nos componentes curriculares convencionais ou em outros criados para essa finalidade. Em uma conversa com uma liderança indígena que é também gestor daquela escola, ele observou que

Então, vamos lá. É... sabemos que a questão da Lei 11.645 é, uma lei que está prevista, uma lei que está prevista e deve ser trabalhada nas escolas não-indígenas. Porém, nós encontramos muitas dificuldades para que essa lei ela seja de fato trabalhada nessas escolas, o índio, ele é tratado como o índio de 1500. Não é considerado protagonista da história e, muitas vezes, ele é visto apenas com o olhar do colonizador. Então, para que essa visão estereotipada sobre o índio seja, desconstruída, é necessário que aspectos culturais e questões que envolvam os saberes indígenas nas escolas não-indígenas sejam é, também trabalhados, por exemplo, temos os conhecimentos tradicionais do pajé, das benzedeiras, que são conhecimentos que são feitos nas comunidades indígenas e que é importante também que seja passado pra as escolas não-indígenas, que são conhecimentos que podem ser trabalhados de maneiras interdisciplinares, em diversas disciplinas, é, mais especificamente, talvez em ciências (...). Isso não impede que outras disciplinas também possam tá trabalhando (...) por exemplo, no português trabalhar gêneros textuais, com bulas, receitas, dentre outras coisas. Em relação a questão dos artesanatos, 
tanto de madeira quanto de cerâmica, também pode ser trabalhados nas aulas de artes, os artesanatos indígenas, as culturas, os caiaques, coxos (sic.), gamelas, né? Trabalhar nas artes, trabalhar na matemática, nas formas geométricas, como o formato redondo, o formato quadrado. Então, os conhecimentos indígenas eles podem sim ser trabalhados nas escolas não-indígenas, a forma de fazer uma cerâmica, dentre outras coisas. Pinturas indígenas, formas geométricas, podem ser trabalhadas em matemática, questões como 0 tipo de fruta que foi utilizado pra fazer aquela tinta, né? Pode ser trabalhado nas ciências e demais disciplinas também, inclusive, os demais adereços indígenas como os cocares, os tipos de aves que são utilizadas para fazer os cocares, os tipos de sementes que são utilizados pra fazer os colares, tipo de coco que faz maracá ou tipo de cabaça. Então, todos esses aspectos podem ser trabalhados nas escolas não-indígenas para que, de fato, a realidade indígena seja executada nas escolas. No que se refere a questão da agricultura, os tipos de plantios, a mandioca, principalmente, a forma como ela é produzida pelas comunidades indígenas, desde o plantio até a colheita, e o processamento na farinheira é algo interessante pra ser trabalhado na sala de aula também de geografia. Essa industrialização do setor primário, secundário, terciário é interessante nas ciências, o tipo de plantação. Também a questão da arquitetura das casas indígenas, o formato, das casas indígenas, de taipa, outras já, apenas casas de palha, outras de madeira, né? Uns formatos que são, principalmente, em algumas aldeias, o formato quadrado, mas, existe aldeias que preservam mais essa questão da arquitetura que é um formato mais redondo. Então, são muitas coisas que podem ser trabalhadas nas escolas não-indígenas referente aos indígenas. Também, o meio ambiente, como que é a preservação dos rios pelos indígenas, a questão dos lixos, a questão das matas, a questão da preservação ambiental e até mesmo, o manejo sustentável desses recursos para que o meio ambiente permaneça como ele é, permaneça de uma forma que possa tá melhorando a saúde da população. (CAMPO. LIDERANÇA PATAXÓ, ALDEIA CORUMBAUZINHO, 25 de setembro de 2019)

Na Aldeia Cahy, o Colégio Estadual Indígena Kijetxawê Zabelê desenvolve um trabalho pedagógico voltado tanto para os indígenas quanto para os não-indígenas, inclusive, com um material didático utilizado no processo de ensino-aprendizagem elaborado por algumas lideranças indígenas em parceria com um grupo de artistas, (CASTRO; FONSECA, 2019). Na Aldeia Boca da Mata, a Escola Indígena Pataxó Boca da Mata, me chamou a atenção desde arquitetura do prédio, de cujo pátio central hexagonal, é milimetricamente ornado com elementos culturais pataxó; até a maneira como articulam, nos materiais didáticos elaborados ou adaptados, os conhecimentos ancestrais aos temas e conteúdos praticados nas escolas não-indígenas. Segundo informado,

[...] a construção desse conhecimento é feito sucessivamente, além do conhecimento que também os alunos já tem com os seus pais, que acaba ajudando [...] Nós temos que adequar os materiais didáticos que nós recebe, nossos livros, né? Nossa matriz curricular nós tem que adequar, por quê? Nós tem tanta coisa riquíssima aqui [...] Construir um texto voltado pra sua comunidade, que forma ela é, quem mora nela, o que é que se planta nela, qual é a vida econômica dessa comunidade, vamos escrever sobre ela, produzir um texto, desenhar 
nossa realidade, no nosso material didático, porque nós não vamos ter um material específico não, nunca vamos ter, porque nunca vamos ter condição de produzir e reproduzir pra distribuir nas escolas não-indígenas [...] É tanto que nossa educação escolar indígena, ela trabalha um pé na comunidade e um pé lá fora da comunidade. Então, são dois pés que nós temos, né?" (CAMPO. LIDERANÇA PATAXÓ, ALDEIA BOCA DA MATA, 2 de dezembro de 2019)

À medida em que fui imergindo no campo para a realização da pesquisa e em contato com os indígenas das aldeias onde estive, notei em cada uma delas que, à revelia do que muitas pessoas propalam sobre o estado de atraso em que vivem, e tomando a citação anterior como referência, me parece que os povos indígenas estão mais em sintonia com as pluralidades culturais do que os não-indígenas. Estar com um pé na comunidade e outro fora dela me parece significar estar atento e conectado, literalmente, com outras formas culturais de existência. Nessa perspectiva, a dizimação a que ainda estão submetidos, se relaciona, em primeira instância, com a perversa colonização praticada e seus desdobramentos, registrando-se aí que, inúmeras gerações indígenas que (sobre)vivem quase que sem nenhum amparo legal.

Em decorrência do processo de formação sociocultural brasileiro, o não aprendizado, desde outrora, das diferenças culturais, valorizando-as, possibilitou que, ao longo destes cinco séculos, a sociedade que daí se originou, tem uma brutal dificuldade em reconhecer e respeitar a diferença. Neste sentido, para que consigamos contribuir na reversão dessa perversa realidade, a educação, as escolas e as práticas docentes precisam introduzir em bases mais significativas, as heranças culturais ancestrais dos povos originários e afro-quilombolas porque

[...] o reconhecimento a gente faz com os alunos em sala de aula [...] A história que tem em livro, não é a verdadeira história. Então, a história que tem no livro, ela é um conto de fada e a gente não gostaria que continuasse assim, a gente gostaria que ela seria contada na realidade [...] A escola não-indígena ela buscasse levar os alunos indígenas lá e trouxesse os dela também pra escola indígena. Um período, um tempo, até ficasse trabalhando dentro da aldeia [...] É na convivência que eles ia aprender. Porque as vezes eles vê o indígena diferente [...] A gente vai falar da nossa cultura aonde a educação não-indígena não vai falar [...] Assim como o indígena vai lá pra fora, o branco pode vir pra dentro da aldeia. Então, é essa parte que eu queria que tivesse uma parceria, uma grande parceria pra o reconhecimento [...] Porque todos são iguais. A gente quer aprender juntos com os quilombolas, os quilombolas com os indígenas, e os não-indígenas também pudesse fazer parte [...] Se colocou uma lei, que fizesse cumprir com a obrigação, com o reconhecimento, porque não adiante ter só o artigo e o número e não fazer cumprir. (CAMPO. LÍDER PATAXÓ HÃ-HÃ-HÃE, ALDEIA RENASCER, 3 de dezembro de 2019)

Se ampliássemos as nossas lentes leríamos que, na perspectiva dos povos indígenas, deveríamos perceber que "uma cidadania que não é apenas um direito de ordem sociopolítica, se constrói também pela problematização teórico-política de sua articulação com as questões sociais” (PORTO, 2019, p. 96).

Nas comunidades rurais e urbanas remanescentes de quilombos do Extremo Sul da Bahia, em 
função da cultura do eucalipto introduzida na região na segunda metade do século XX e dos impactos desastrosos ocasionados pelas multinacionais aí instaladas, inúmeras famílias negras foram desapropriadas, inclusive porque, desconheciam os seus direitos como descendentes quilombolas, condição que passou a ser resolvida no início do século XXI quando da atuação da Fundação Palmares, órgão do extinto Ministério da Cultura, nas regiões e localidades onde se registra a presença desses grupos familiares que passaram a reconhecer-se como quilombolas.

Durante as investidas de campo realizadas ao longo das pesquisas do estágio pós-doutoral e nas interlocuções com os antigos moradores das comunidades remanescentes de quilombos para melhor conhecê-las, por meio dos seus arquivos de memória pude acessar passagens históricas daquelas comunidades que ainda podem revelar inúmeras outras pesquisas. Rememorando a Comunidade Arara de sua infância, um senhor octogenário lembra que,

[...]naquele tempo ninguém tinha sapato, papai fazia aquelas "precatas" (sic.) de couro cru pra andar, pra poder ir trabalhar [...] me lembro que eu falava assim: eu vou mandar papai fazer uma "pescata" pra mim, isso daí eu me lembro bem [...] como meu pai não tinha condições de pagar ninguém, fez a primeira roça, ai "prantou”, fez na raça, "prantou" feijão, "prantou" milho, "prantou" banana, "prantou" cana, "prantou" cacau e a gente tinha de um "cado" (sic.) de tudo que era de alimento, nós tinha de cada coisa um pouquinho [...] a brincadeira era cavalo de pau, depois que veio o baile (sic.), o samba, o batuque [...] a primeira escola que teve aqui nessa comunidade foi ali onde é a sede de Saraiva [...] as festas era mais de gente grande [...] a gente assistia mais era quando vinha a brincadeira de Reis [...] ou quando tinha algum baile na casa de algum parente, ou quando tinha um samba também, um "taipe de casa" (sic.) aí as vezes a gente ia no meio junto com nossos pais e participava daquele movimento [...] é, brincadeira de Reis é bonito [...] ah, você já ouviu falar na marujada? Era aquele tipo, só que era no sistema mais diferente, ali tinha as "contra-dança" (sic.) tinha seus cânticos de Reis e tinha o "boi janeiro" (sic.) [...] mas hoje em dia ninguém se lembra mais, o desenvolvimento chegou e aí as coisas, aquelas coisas que a gente podia, hoje em dia não pode [...] eu tô me referindo ao desenvolvimento em primeiro lugar na educação, em segundo lugar nos meios de comunicação através de estradas e em terceiro lugar com o desenvolvimento dos eletrônicos, pra mim são essas três questões. (CAMPO. ANCIÃO, COMUNIDADE ARARA, 9 de julho de 2019)

Da maneira como elaborados e nos possibilitado acessar, os fragmentos dos arquivos da memória remonta, aleatoriamente, épocas vividas, recordações e se constitui como um tipo de registro privilegiado que os livros e demais materiais didáticos não alcançam. Dizendo de outra maneira, por exemplo, na perspectiva da micro-história (GINZBURG, 1976) os arquivos da memória nos possibilita um aprendizado da história que, partindo das singularidades individuais, nos possibilita compreender um grupo social ou uma sociedade como um todo. Ou, como observado por Muniz Sodré (2017, p. 27),

[...] num espaço-mundo cada vez mais comprimido pela temporalidade imediata dos circuitos eletrônicos, é vital figurar um contexto também social ou global, em que dife- 
rentes modos de teoria ou de proposições com alcance conceitual sejam confrontados ou postos em situação dialógica. Isto implica um importante deslocamento epistêmico porque o que será então posto em pauta cognitiva não é mais apenas a revelação sociológica ou antropológica da existência de um sistema simbólico coerente e sim o reconhecimento de outra forma teórica que se possa designar como "filosófica" (porque este é o nome excelso do intercâmbio teórico no Ocidente) e com a qual seja possível a "dialogia" que designamos como transcultural.

Desse modo, essas outras formas de ser-estar-pensar-sentir o mundo aqui entendidas como pluriepistemologias, se constituem como possibilidades potenciais da promoção de uma abordagem intercultural (CANDAU; ROSSO, 2010) pautada na (re)descoberta e (re)valorização da herança cultural indígena e quilombola no contexto das situações de ensino-aprendizagem da educação básica, esta que, aos nossos dias, ainda que tomemos como referências as obrigatoriedades, sugestões e tentativas conferidas desde a Lei de Diretrizes e Bases (LDB) 9.394/96 e dos Parâmetros Curriculares Nacionais no sentido da efetivação de currículos e práticas curriculares mais plurais e diversos, continua dando lugar a práticas de docência que muito pouco, quase nada, valorizam a pluralidade e a diversidade presentes nas salas de aula.

Obviamente, não pretendo aqui demonizar ou desqualificar os esforços envidados diariamente por colegas da escola básica em seus fazeres docentes cotidianos. 0 que aqui está sendo posto em questão é que em decorrência de uma formação escolar e profissional colonizada e cartesiana que muitas e muitos de nós obtivemos no passado, estas ainda se encontram firmemente arraigadas nas concepções e práticas de docência que, a rigor, fundamentalmente, são herdeiras da concepção epistemológica fundante da empresa colonizadora que se fez por meio de exercício perverso da subjugação, do embotamento, da violência e da ignorância cultural.

Historicamente, isso significou uma nova maneira de legitimar as já antigas ideias e práticas de relações de superioridade/inferioridade entre dominantes e dominados. Desde então demonstrou ser o mais eficaz e durável instrumento de dominação social universal, pois dele passou a depender outro igualmente universal, no entanto mais antigo, o intersexual ou de gênero: os povos conquistados e dominados foram postos numa situação natural de inferioridade, e consequentemente também seus traços fenotípicos, bem como suas descobertas mentais e culturais. Desse modo, raça converteu-se no primeiro critério fundamental para a distribuição da população mundial nos níveis, lugares e papéis na estrutura de poder da nova sociedade. Em outras palavras, no modo básico de classificação social universal da população mundial. (QUIJANO, 2005, p. 118).

Com um dos interlocutores da pesquisa encontrei pistas valiosas sobre a Comunidade Volta Miúda. Por meio delas, é possível ampliarmos o nosso entendimento sobre as histórias das populações negras no Extremo Sul da Bahia a partir do processo de ocupação do lugar em decorrência dos desdobramentos da ação colonizadora. Revisitando os conhecimentos obtidos a partir da memória dos seus mais velhos e de outras fontes de referência, disse: 
[...] nós temos a árvore genealógica, eu vou te mostrar. Quando você chegar na comunidade... eu fiz na nossa sede da associação e coloquei ela grandona, com algumas pessoas antigas com as fotos e alguns conflitos, eu coloquei isso. Montei ela, a antropóloga fez a árvore com as famílias [...] e em cima e nas laterais eu coloquei as fotos de algumas pessoas [...] E coloquei a frase, a luta dos nossos ancestrais [...] No nosso sítio arqueológico eu só via as pessoas dizer bem assim: em Volta Miúda tinha uma senzala [...] Meus antigos fala sanzala, certo? Meus antigos fala casarão, entendeu? E além dessa senzala, existe um cemitério da época de 1818 [...] O IPHAN veio aqui, fez a visita no cemitério, hoje existe um só túmulo lá, que o resto a empresa quebrou tudo, plantaram eucalipto, só que quando ela viu que ali era um cemitério, ela recuou [...] Você chega lá, nós temos esse túmulo gigantesco [...] Esse túmulo ele era de 1890. Esse túmulo ele é da época de Helvécia, das comunidades [...] Por exemplo, no parecer do IPHAN, Volta Miúda era uma fazenda de café que tinha vinte escravos trabalhando [...] Então, dessa época, Volta Miúda tinha Volta Miúda de branco e Volta Miúda de preto [...] Então, na história, no parecer, são vinte escravos que eles trouxeram da época, e depois os escravos foi tendo suas famílias [...] Nós sabemos que hoje, ainda dessa época, tem umas famílias aí com esse sobrenome, desse pessoal que vieram. Acho que de lá pra cá, eles passaram a ter relação com as próprias pessoas escravos que eles tinham trazido na época, então, tem o sobrenome dessas pessoas, dos brancos hoje, por exemplo a família Krull [...] e Metzker, esses dois sobrenomes [...] Então, resumindo pela história, então, veja de quando nós sofremos sobre essa história, veja desde onde nós viemos sofrendo, imagina". (Campo. Presidente da Associação dos Moradores da Comunidade Volta Miúda, 25 de setembro de 2019).

No primeiro vintênio do século XXI, tem se intensificado as lutas e processos de resistência em defesa dos direitos civis e humanos dos povos indígenas e quilombolas. No contexto em que elaboro este escrito, o procurador-geral da República, em nota recente, tornou público a extinção da Secretaria dos Direitos Humanos e Defesa Coletiva, órgão que protegia as terras indígenas e quilombolas contra as invasões.

Com a extinção dessa secretaria, os descendentes dos povos originários e as populações quilombolas ficam ainda mais vulneráveis a quaisquer formas de práticas de agressão e violência nos territórios em que (sobre)vivem. Entendendo que se constitui função política da educação e do ensino cuidar dos direitos de todos os povos, por meio de currículos e práticas de docência comprometidas com as culturas populares poderemos promover abordagens de temáticas diversas, integrativas e inclusivas das nossas identidades socioculturais.

Palco de disputas e conflitos no âmbito das relações de poder e dominação, a cultura pode também se tornar um importante terreno de luta de povos e comunidades que se utilizam de sua ancestralidade, sua língua materna, suas tradições, memórias, mitos, celebrações, danças, cantos, ritos e, sobretudo, de seu imaginário como forma de resistência a processos de dominação política, econômica e ideológica, constituindo dessa forma estratégias de sobrevivência social. (ABIB, 2019, p. 2). 
Portanto, a promoção das culturas populares nos processos de ensino-aprendizagem pode ser entendida como uma poderosa ação política e metodológica na defesa e salvaguarda das nossas tradições culturais. As salas de aulas e os materiais didáticos considerados oficiais estão muito distantes de conseguir abordar a vastíssima história e extensão cultural que este país possui.

Tem muita coisa, viu? Não sei se eu vou lembrar tudo porque, tempo, nós era pequena, é tempo de um tostão e duzentos réis. Nós ia comprar sal, sabão, duzentos réis. Aí a gente não tinha licença de passar pro lado de dentro de barcão (sic.) o senhor tinha que receber tudo por lado de fora. Eles pegava lá e traz cá pra dá a gente, que a gente pedia e eles vem dá, traz. Mas a gente nunca tinha a licença de passar pro lado de lá. E, a gente foi cortado (sic.), passado muito fraqueza, que era gente muito fraco. Nós cortava lenha, corte de lenha, na Bahia e Minas. É, cortar lenha. Tinha um lugar que chamava Tombador (sic.) o senhor jogasse a lenha lá pra cair lá embaixo, carregava, botava na beira do rio pra canoa pegar pra atravessar lado de lá pra a Bahia e Minas pegar. Tempo de trem de ferro, pra pegar pro lado de lá. E, a gente trabalhava em roça, tinha, até hoje tem muita gente que não entende o que eu falo, que a gente prantava (sic.) a manaíba (sic.) assim de fincão (sic.), não é como hoje que a gente fala cavar e botar não, de Fincão, era uma varinha fininha de ponta, agora o senhor enfia essa varinha no chão e faz um buraquinho, agora enfia a manaíba. É assim que a gente trabalhava. E carregava água camuca (sic.), butija (sic.), butija, uma é de ferver água pra café e outra de carregar água pra beber na roça, chamava butija. É, e a gente tratar, que o povo tratava. Hoje em dia, é tão diferente. É, hoje em dia, a gente fala o senhor, é mucê (sic.) que chamava, quando falava mucê é eu chamando, falando o senhor. Era mucê. É, falava, e, a gente comia o quê? Orelha de pau. O senhor não sabe o que é orelha de pau, né? É, a gente comia. Hoje em dia nem existe ele mais. E folha de veado, comia também. Hoje, uma folha que a gente chamava folha amargosa (sic.), o senhor tinha que esfregar até sair o sumo tudo, chega sair um sumo verdinho. Agora, era pra botar na carne pra comer. E quem falou que o senhor que usava feijão e arroz? Era só de ano em ano. Ocasião de Sexta-feira da Paixão. Só que come arroz. Pra trás é só o pirão mexido a farinha, pirão e água e a carne. Nós foi criado tudo assim. E, tratar mãe e o pai, é outra coisa [...] Quando morria uma pessoa, é cantar nagô. Cantar nagô ao redor do caixão rodando o caixão [...] E é escolhido. Era escoIhido só esse já velho, menino novo não ia pra cantar [...] Eu conheci a minha avó. Ela era uma mulherona grandona, marrava uma toalha grande na cintura pra poder ir cantar, né? (Campo. Anciã, Comunidade Quilombola Volta Miúda, 01 de dezembro de 2019).

E a orelha-de-pau (Pycnoporus sanguineus), o/a leitor/a conseguiu lembrar o que significa? É um tipo de fungo, espécie de ramagem de cuja forma imita uma orelha e brota nos troncos das árvores caídas em muitas regiões florestais. De utilização variada, pode ser usado desde a preparação de receitas culinárias até em usos medicinais. Enfim, no contexto de uma sala de aula - ou fora dela - são inúmeras as estratégias a que se pode lançar mão para o aprendizado e a produção de conhecimento. Como discutido ao longo deste paper, os repertórios mnemônicos e as heranças intelectuais afro-indígenas se constituem, a um só tempo, em estratégia metodológica e abordagem temática imprescindíveis para que (re)aprendamos a ser-estar-viver-sentir a diferença. 


\section{CONSIDERAÇÕES FINAIS}

Em uma visada, ainda há muito o que fazer no sentido de acessarmos esses outros sujeitos históricos, os seus modos de vida e suas contribuições intelectuais. Por meio da conjunção do pensamento pluriepistêmico e da abordagem intercultural é possível promover práticas de docência na educação básica calcadas na valorização e no respeito as diferenças culturais, estratégia que, certamente, poderá contribuir para que estejamos em consonância com as nossas ancestralidades indígeno-afrobrasileiras. Por fim, que as heranças culturais indígeno-quilombolas nos possibilite revelar muitos outros conhecimentos sobre nós mesmos. Sigamos.

\section{REFERÊNCIAS}

ABIB, Pedro Rodolpho Jungers. Culturas populares, educação e descolonização. Revista Educação em Questão, Natal, v. 57, n. 54, p. 1-20, e-18279, out./dez. 2019.

BATISTA, Maria Geovanda. Processos de etnogênese dos Pataxó em Cumuruxatiba no Município do PradoBA. Revista da FAEEBA - Educação e Contemporaneidade, Salvador, v. 19, n. 33, p. 1-12, jan./jun. 2010.

CANDAU, Vera Maria Ferrão; ROSSO, Kelly. Interculturalidade e educação na América Latina. Revista Diálogos Educacionais, Curitiba, v. 10, n. 29, p. 151-169, jan./abr. 2010.

CASTRO, Laura; FONSECA, Cacá. Kijetxawê Zabelê: Aldeia Kaí. Salvador: Sociedade da Prensa/ EDITÓRA, 2019.

DO CARMO, Alane Fraga. Colonização e escravidão na Bahia: a Colônia Leopoldina (1850-1888). 2010. Dissertação (Mestrado em História Social) - Faculdade de Filosofia e Ciências Humanas, Universidade Federal da Bahia, Salvador, 2010.

GINZBURG, Carlo. 0 queijo e os vermes. 0 cotidiano e as ideias de um moleiro perseguido pela Inquisição. São Paulo: Companhia das Letras, 2006.

MATO, Daniel. Diferenças culturais, Interculturalidade e Inclusão na Produção do Conhecimento e Práticas socioeducativas. In: CANDAU, Vera Lucia (org.). Educação Intercultural na América Latina. Rio de Janeiro: 7 Letras, 2009. p. 74-93.

NUNES NETO, Francisco Antonio. Entre as demandas, os limites e as possibilidades: o ensino e as relações étnico-raciais. In: MACEDO, Yuri Miguel; SANTOS, David Kaique Rodrigues dos; MAIA, 
Cláudia Braga. Inclusão e diversidade na educação: desafios e possibilidades. Porto Seguro: Editora Oyá, 2019. p. 17-78

PORTO, Helânia Thomazine. Processos comunicacionais, identitários e cidadãos: Pataxós em “territórios" de resistências e de utopias. 2019. 278 f. Tese (Doutorado em Ciências da Comunicação) - Universidade do Vale do Rio dos Sinos,

São Leopoldo, RS, 2019.

QUIJANO, Anibal. Colonialidade do poder, eurocentrismo e América Latina. In: A colonialidade do saber: eurocentrismo e Ciências Sociais. Perspectiva latino-americanas. Buenos Aires: Conselho Latino-Americano de Ciências Sociais (CLACSO), 2005. p. 117-142.

SANTANA, Gean Paulo Gonçalves. Vozes e versos quilombolas: uma poética identitária e de resistência em Helvécia. 2014. 265 f. Tese (Doutorado) - Programa de Pós-Graduação em Letras da Universidade do Estado da Bahia, Pontifícia Universidade Católica, Rio Grande do Sul, 2014.

SANTOS, Valdir Nunes dos. A dança bate-barriga em Helvécia (Bahia/Brasil): uma performance afrobrasileira de coesão social. 2017. 333 f. Tese (Doutorado em Belas Artes) - Faculdade de BelasArtes, Universidade de Lisboa, Lisboa, 2017.

SODRÉ, Muniz. Pensar nagô. Petrópolis, RJ: Vozes, 2017.

WALSH, Catherine. Interculturalidade Crítica e Pedagogia Decolonial: in-surgir, re-existir e re-viver. In: CANDAU, Vera Lucia (org.). Educação Intercultural na América Latina. Rio de Janeiro: 7 Letras, 2009. p. 12-41. 
1 Bolsista do Programa Nacional de Pós-Doutorado da CAPES no Programa de Pós-Graduação em Educação, Universidade Federal da Bahia - UFBA; Professor Permanente do Programa de Pós-Graduação em Ensino e Relações Étnico-Raciais, Universidade Federal do Sul da Bahia UFSB; Líder do Grupo de Pesquisa Práticas e Representações Culturais em um Lugar no Mundo - UFSB; Membro dos Grupos de Pesquisa O Som do Lugar e o Mundo, e GRIÔ: Culturas Populares, Ancestralidades e Educação UFBA. E-mail: xicco7@hotmail.com

2 Doutor em Ciências Sociais Aplicadas à Educação UNICAMP; Supervisor da Pesquisa; Professor Permanente do Programa de Pós-Graduação em Educação da Universidade Federal da Bahia - UFBA; Pós-Doutor em Estudos Lusófonos pela Universidade de Nanterre La Defense-Paris $X$ e em Ciências Sociais pela Universidade de Lisboa; Líder do Grupo de Pesquisa GRIÔ: Culturas Populares, Ancestralidades e Educação; Capoeirista, músico e compositor de samba. E-mail: pedrabib@gmail.com

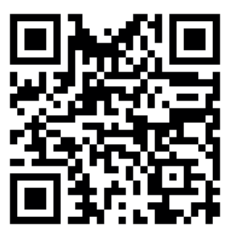

A autenticidade desse artigo pode ser conferida no site https://periodicos. set.edu.br

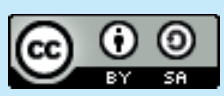

Este artigo é licenciado na modalidade acesso abertosob a Atribuição-Compartilhalgual CC BY-SA

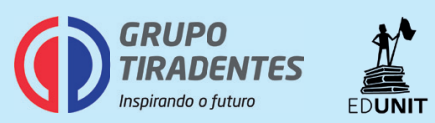

